\title{
Classification and evaluation of uncertain influence factors for farm machinery service
}

\author{
Wu Caicong ${ }^{1,2^{*}}$, Cai Yaping ${ }^{3}$, Hu Bingbing ${ }^{1}$, Wang Jie ${ }^{1}$ \\ (1. College of Information and Electrical Engineering, China Agricultural University, Beijing 100083, China; \\ 2. Department of Soil \& Crop Sciences, Texas A\&M University, College Station 77843, USA; \\ 3. Department of Geography and Geographic Information Science, UIUC, Urbana-Champaign 61820, USA)
}

\begin{abstract}
Uncertainty extremely interferes with the execution of farm machinery operation. Treating uncertainties is especially important for machinery cooperatives providing social service since they face more uncertain influence factors (UIFs) than family farms. Under social service circumstance, uncertainties may arise from participants and environments. Classification and evaluation of UIFs were studied in this research. According to the production system, 32 UIFs are defined and classified into six categories, which include supply, demand, interactivity, nature, society and others. Uncertainty composite index (UCI) is defined to evaluate the importance of UIFs, which is the square root of the product of occurrence frequency (OF) and impact degree (ID) calculated from the well-designed questionnaire responded by farm machinery operators. UCI is divided into five ranks based on normalization distribution test to illustrate the level of importance. Results from questionnaire showed that natural UIFs have an extreme impact on farm operation, UIFs of the demand and the supply have a serious influence on farm operation, UIFs of interactivity cannot be ignored, and social UIFs have a weak impact on farm operations. This study discovered the uncertainty problems under the specific circumstance of farm machinery service, which may provide a theoretical basis and potential methods for risk management of machinery cooperatives.
\end{abstract}

Keywords: uncertainty, uncertain influence factor (UIF), classification, uncertainty composite index (UCI), machinery cooperatives

DOI: $10.25165 /$ j.ijabe.20171006.3045

Citation: Wu C C, Cai Y P, Hu B B, Wang J. Classification and evaluation of uncertain influence factors for farm machinery service. Int J Agric \& Biol Eng, 2017; 10(6): 164-174.

\section{Introduction}

The term uncertainty has different definitions for various disciplines ${ }^{[1-7]}$. In agricultural domain, the sources, classifications, impacts, evaluations and handling strategies of uncertain factors were extensively explored

\section{Received date:2016-11-29 Accepted date: 2017-10-20}

Biographies: Cai Yaping, $\mathrm{PhD}$ candidate, research interests: mobile information collection, Email: caicai_pku@163.com; Hu Bingbing, Master candidate, research interests: mobile management offarm machinery, Email: 1353232901@qq.com; Wang Jie, Master candidate, research interests: mobile management of farm machinery, Email: 1071825176 @qq.com.

*Corresponding author: Wu Caicong, $\mathrm{PhD}$, Associate Professor, research interests: location-based service of farm machinery. College of Information and Electrical Engineering, China Agricultural University, Beijing 100083, China. Tel: +86-1062736746, Email: wucc@ @au.edu.cn. for various applications ${ }^{[8-15]}$. Farmers have to be prepared to face uncertainties by adjusting or even reschedulingtheir original farming plan ${ }^{[16]}$, which is also supported by our investigation in China Huishan Dairy Holdings Company Limited (Huishan) and several cooperatives providing social service. For farm machinery service, uncertainties mainly from two aspects, internal production system and external environment, may cause serious impact on farm machinery operations. Therefore, intensive attention has been paid to this area,which promotes increasing researches on handling uncertainties for farm machinery service, such as uncertainty in supply chain management ${ }^{[8]}$, scheduling under uncertainty ${ }^{[17]}$, etc. The fact is that the uncertainty with possibility above $6 \%$ will lead to unstable solutions; while in the case with $20 \%$ possible uncertainty, only 
$75 \%$ of the derived solutions will coincide with the baseline solution ${ }^{[18]}$. Additionally, David ${ }^{[19]}$ proposed that uncertain impacts should be considered during farm machinery allocating and scheduling at the earliest stage. Similarly, Bochtis et al. ${ }^{[16,20]}$ considered uncertainties in advance to improve the efficiency of scheduling model. In fact, scheduling model simply with certainty constraints without considering uncertainties has less practicability ${ }^{[21,22]}$. Most works mainly focus on how to handle uncertainty in farm machinery scheduling, while few works have been done to classify and evaluate the uncertainty.

Nowadays, farm machinery service is popular and has a big potential market in China, where cooperatives and individuals with farm machinery as suppliers provide flexible farm machinery service covering a variety of farm operations to customers, including cooperatives or individuals who have insufficient farm machinery or labors. Under this circumstance, the property ownership of production factors such as field, crop, machinery, implement and labor, become complex comparing to traditional self-sufficient family farms ${ }^{[23]}$. Meanwhile, uncertainties also become complex and may emerge from the production system and its social and natural environment ${ }^{[24-26]}$.

For machinery cooperatives ${ }^{[27]}$ to survive and prosper in turbulent and unpredictable environments, decreasing uncertainty is assumed to be of major importance ${ }^{[14,28]}$. Uncertainties, such as mechanical failure and weather change $^{[29,30]}$, would impact the implementation of a farming plan made at the beginning of the growing season, especially for machinery cooperatives that providing services to external customers ${ }^{[23]}$. How to handle uncertainties reveals the capacity of a machinery cooperatives to adjust according to changes and exploit opportunities from internal and external changes ${ }^{[13]}$. As mentioned above, most researches just focus on how to handle uncertainty in farm machinery service, but few researches have been done to systematically identify, classify, and evaluate the uncertainty in detail ${ }^{[17]}$, which should be fulfilled prior to handling uncertainties.

In this study, we mainly define the classification of uncertain influence factors, propose uncertainty composite index to evaluate them, and analyze the results from a well-designed questionnaire based on our strategy ${ }^{[25]}$. Finally, the uncertainties faced by machinery cooperatives engaged in social service are comprehensively understood.

\section{Materials and methods}

\subsection{Framework of farm machinery service}

To understand the framework of farm machinery service is essential to identify uncertainties within it. Figure 1 shows the basic framework of a production system of farm machinery service ${ }^{[31]}$. The system has two main participants, the cooperative with work units that will be explained later and the customer with fields, which represent the supply side and the demand side respectively. The two participants carry out transactions under natural and social-economic environments. Most of the business of farm machinery service in China is negotiated through oral agreements through telephone or instant-messaging software. The transaction with weak constraint may change before or during farm machinery service. Oral agreements are non-guaranteed contracts with hidden uncertainty.

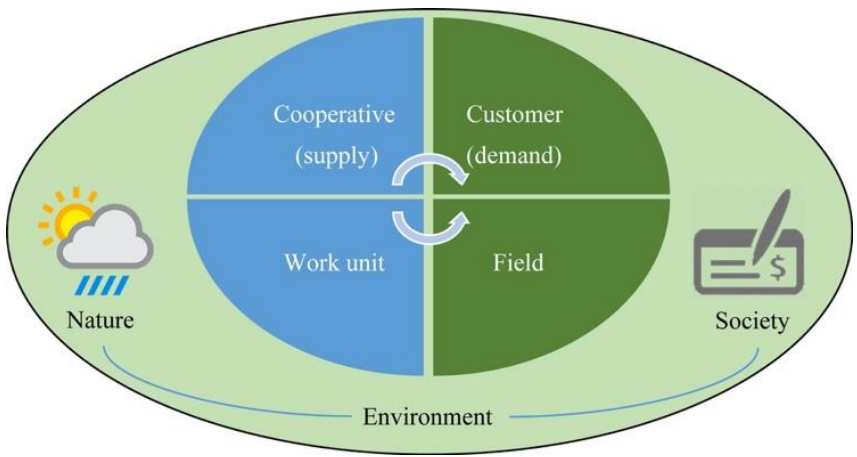

Figure 1 Framework of production system of farm machinery service

In general, a work unit mainly consists of tractor, implement, and operator ${ }^{[32]}$. With this concept, under social service circumstance, one machinery cooperative is similar to a fleet ${ }^{[33,34]}$ with multi-working groups, each of which is comprised of a different number of work units $^{[18]}$

As Figure 2 shows, these units not only consist of traditional components but also require auxiliary operators to provide services such as material supplement and parts maintenance. Auxiliary operators are unified dispatched by manager or group leader of machinery 
cooperative. Different working groups can conduct farm operations in parallel, while different work units within each working group can perform farm operations in both parallel and sequential (an example of farm operations sequences are shown in Figure 3$)^{[33]}$.

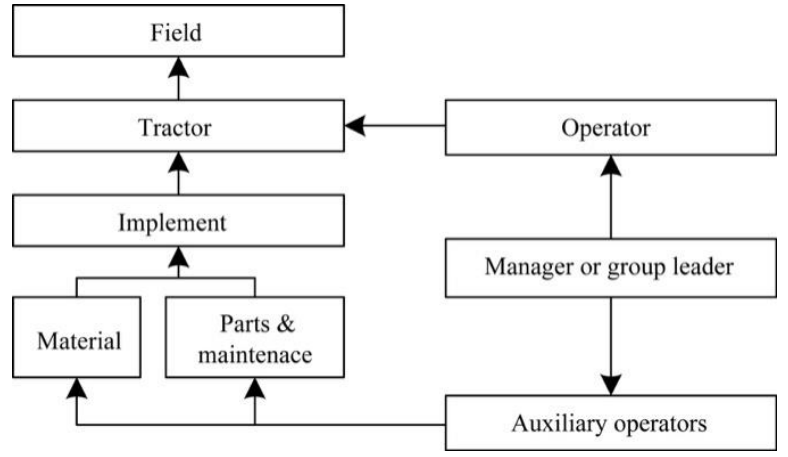

Figure 2 Composition of work unit in working group of farm machinery cooperative

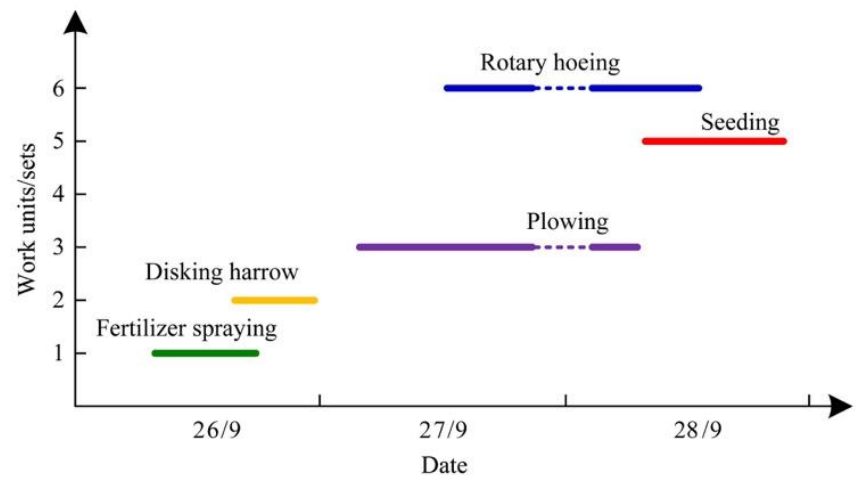

Note: Segments overlap in $X$-axis stands for farm operating in parallel. Dash line stands for operation interrupt because of nightfall.

Figure 3 An example of sequences of five farm operations in one field with an area of $12.5 \mathrm{hm}^{2}$ in Beijing, 2014 ${ }^{[23]}$

In Figure 3, different farm operations require different numbers of work units depending on the operation efficiency, ranging from one work unit from fertilizer spraying operation to six work units from rotary hoeing operation, which shows the complexity of scheduling. In addition, we can indicate the relationship of different work units in the inner machinery cooperative is also highly complex. Uncertainties may arise from any operation and its inner cooperative, which will in turn influence the scheduling and dispatching procedures, and cooperative management. Therefore, we unitized questionnaire to systematically study the uncertainties within this production system.

\subsection{Questionnaire design}

Based on the above analysis of the framework, it is reasonable to conclude that uncertainties lie in participants, environment and their interactivities. Thirty-two UIFs are defined and classified into six categories, which will be discussed in detail in Section 3.

To measure occurrence frequency (OF) and impact degree (ID) of 32 UIFs within farm machinery service, questionnaire method was applied. In the questionnaire, occurrence frequency is divided into five levels including always, often, usually, occasionally and never. Similarly, impact degree is divided into five levels including deadly, seriously, moderately, slightly and none. For each level of either occurrence frequency or impact degree, it is ranked and with a unique value based on the rank, as shown in Table 1. For further analysis based on the questionnaire, $V_{O F}$ is defined as the average value of occurrence frequency for a specific UIF, and $V_{I D}$ is defined as the average value of impact degree of a specific UIF. In addition, according to the values defined in Table 1, the value range of either $V_{O F}$ or $V_{I D}$ is $[0,4]$.

Table 1 Rank and value of $O F$ and ID

\begin{tabular}{cccc}
\hline Rank & OF & ID & Value \\
\hline $1^{\text {st }}$ & never & none & 0 \\
$2^{\text {nd }}$ & occasionally & slightly & 1 \\
$3^{\text {rd }}$ & usually & moderately & 2 \\
$4^{\text {th }}$ & often & seriously & 3 \\
$5^{\text {th }}$ & always & deadly & 4 \\
\hline
\end{tabular}

The questionnaire contains two parts, basic questions and professional questions about UIF that is addressed in Sections 4.1 and 4.2, and all questions are single-choice. We released the questionnaires through Google Docs and Sojump.com successively in 2014. Operators (usually called drivers in China) were invited to complete the questionnaires online. Most of the operators were indirectly invited by their managers or group leadersto guarantee the response quality.

Finally, 90 questionnaires, covering seven provinces in China including Beijing, Tianjin, Heilongjiang, Xinjiang, Hebei, Shanxi and Jiangsu, were collected online. After filtering out failure and unfinished questionnaires, 69 effective questionnaires were used as research dataset. Statistical analyses were conducted using IBM SPSS Statistics 19 for Windows.

\subsection{Methodology}

For the previous two sections, framework and 
questionnaire are addressed to clarify our research object and data source used for analysis. Figure 4 summarizes the methodology, which consists of seven main steps: 1) The basic framework of a production system of farm machinery service was analyzed, which is the main source of uncertainties ${ }^{[22]}$. 2) The theoretically designed 32 uncertain influence factors (UIFs) ${ }^{[22]}$ were grouped into six categories. 3) Given the definition of uncertainty composite index $(U C I)$ and its formulation, each UIF can be evaluated. 4) The questionnaire was designed and spread out through the Internet, and valid answers were collected as inputs for UCI calculating. 5) The dataset was cleaned for further research. 6) Profound and detailed discussion and analysis were conducted for major UIFs. 7) The categories and each UIF were revised according to the analysis result.

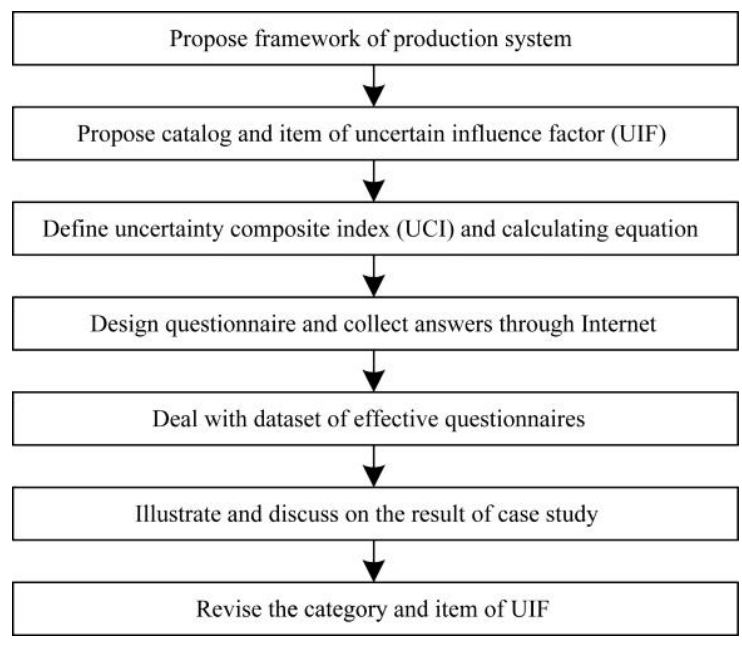

Figure 4 Methodology workflow

\section{Classification and evaluation}

\subsection{Category}

As Figure 1 shows, the classification of UIF can be divided into six categories that are demand, supply, interactivity, nature, society and others, according to the sources of uncertainties. Each category includes different UIFs are shown in Table 2 and are discussed in the following. The brutal force method is applied to include as many UIFs as possible.

\subsection{UIF}

\subsubsection{UIF of demand}

This kind of UIFs come from customer representing demand side and would affect farm machinery operations. The UIFs mainly include operation order increase, operation order cancellation, operation area change, operation location change, operation sequence change, operation duration change, operation price change, operation quality change, and etc.

\subsubsection{UIF of supply}

These kind of UIFs arise from machinery cooperative representing supply side and would affect farm operations. The UIFs mainly include machine degradation, mechanical failure, parts supply delay, gas supply delay, maintenance delay, production material supply delay, operation skill defect, operator sudden illness, and etc.

\subsubsection{UIF of interactivity}

These kind of UIFs are from interactivities between demand side and supply side and would affect farm machinery operation. The UIFs mainly include miscommunication with the customer, obstruction by customer, unprofessional operation, agronomy incompatibility, inaccurate farmland location, and etc.

\subsubsection{UIF of nature}

This kind of UIFs come from the natural environment and would affect farm machinery operation. The UIFs mainly include sudden weather change, pest or disease outbreak, soil not suitable for operation, and etc.

\subsubsection{UIF of society}

This kind of UIFs rise from government policy and market environment and would affect farm machinery operation. The UIFs mainly include government compulsory operation, government fine, interference by evil forces, malignant competition, machine purchase subsidy change, operation subsidies change, and etc.

\subsubsection{UIF of other sources}

Other UIFs, such as road traffic accident, way losing, and etc., do not belong to the previous categories.

\subsection{Definition of UIF}

Classification and definition of UIF are illustrated in Table 2.

\subsection{Evaluation}

Uncertainty composite index (UCI is defined as the root of $V_{O F}$ multiplied by $V_{I D}$ to evaluate the importance of UIF, shown in Equation (1). Since we have many UIFs, UCI can be a good indicator to help us find the most important UIFs for further research.

$$
U C I=\sqrt{V_{O F} \cdot V_{I D}}
$$


Table 2 Classification and definition of UIF for farm machinery service

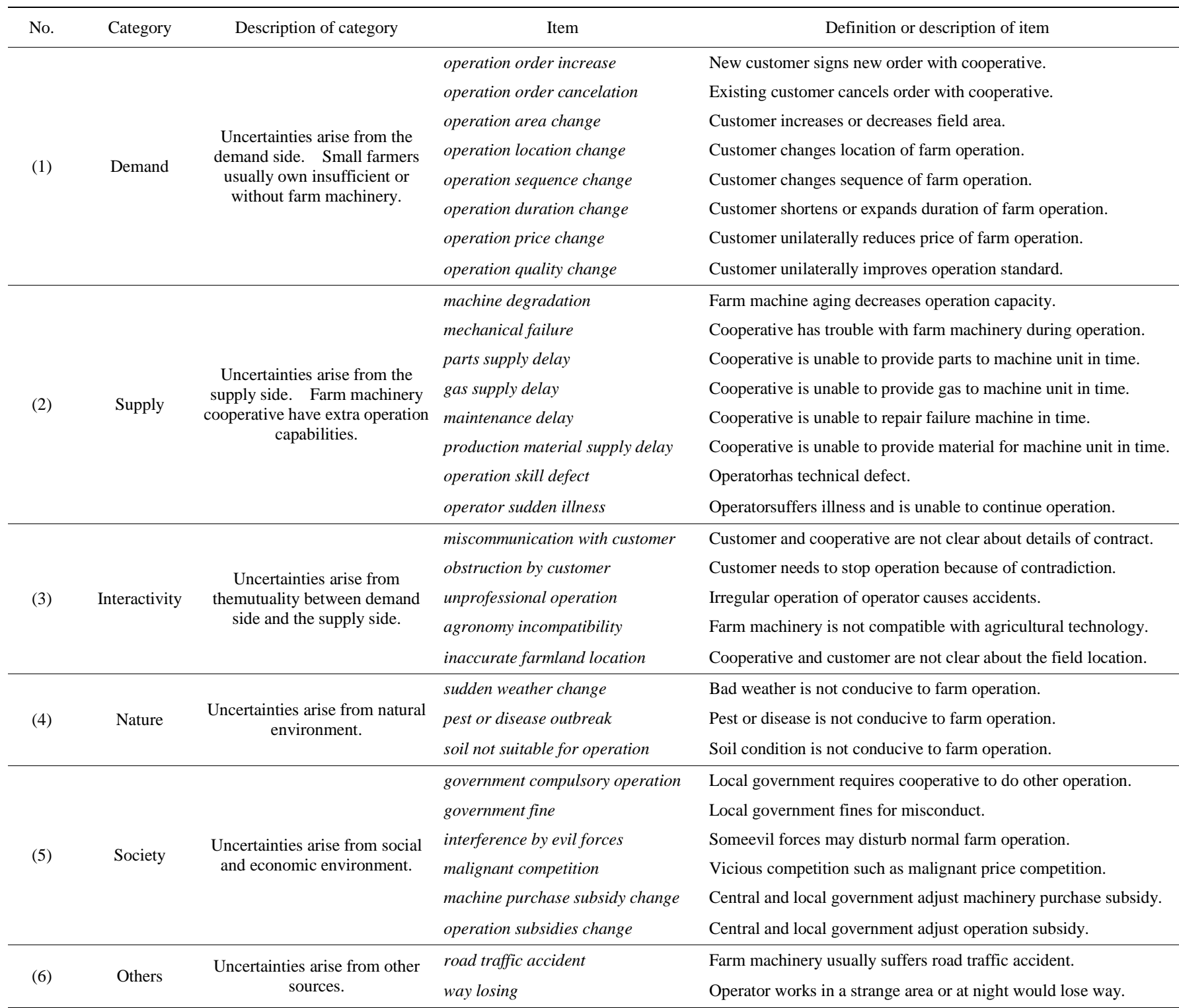

Clearly, $U C I$ has a positive correlation to $V_{O F}$ and $V_{I D}$. Since $V_{O F}$ multiplied by $V_{I D}$, the two items constrain each other, and only both high $V_{O F}$ and large $V_{I D}$ will lead to a high value of $U C I$. $U C I$ is consistent with our judgment and common sense, thus we utilize it to evaluate UIFs. There are two extreme cases. One is that if a UIF with 4 $V_{O F}$ and $0 V_{I D}$, it will be ignored since it has $0 U C I$. For this situation, the UIF has almost no impact on machinery service and can be ignored. Another one is that if a UIF with $0 V_{O F}$ and $4 V_{I D}$, again it will be ignored since $U C I$ is 0 . For this case, the UIF seems to never happen and can be ignored. The range of $U C I$ is between 0 and 4 given the ranges of $V_{O F}$ and $V_{I D}$.

To distinct the uncertainty degree, $U C I$ is divided into five ranks as Table 3, which is well addressed in Section 4.2.2.
Table 3 Rank of uncertainty composite index $(U C I)$

\begin{tabular}{ccl}
\hline Rank & UCI & \multicolumn{1}{c}{ Description } \\
\hline 1 & {$[0.0,0.4]^{*}$} & $\begin{array}{l}\text { UCI has little impact on farm machinery operation, } \\
\text { which can be almost ignored. }\end{array}$ \\
2 & {$[0.4,0.8]$} & $\begin{array}{l}U C I \text { has a weak impact on farm machinery operation, } \\
\text { which can be ignored in most cases. }\end{array}$ \\
3 & {$[0.8,1.2]$} & $\begin{array}{l}\text { UCI has an ordinary impact on farm machinery } \\
\text { operation, which should be emphasized. } \\
\text { UCI has a strong impact on farm machinery operation, } \\
\text { which should be paid more attention. } \\
\text { UCI has an extreme impact on farm machinery } \\
\text { operation, which should be always paying attention to. }\end{array}$ \\
\hline
\end{tabular}

Note: ${ }^{*} U C I$ is greater than or equal to the minimum value, and less than the maximum value.

\section{Results and discussion}

\subsection{Basicinformation of questionnaire}

Histogram of age as shown in Figure 5a indicates that the respondents are mainly young and middle-aged. Histogram of seniority as shown in Figure 5 b indicates 
most of the respondents are proficient operators with more than 5 years working experience. Given the basic information of respondents, we claim that they are qualified to answer the professional questions focusing on UIFs based on their experience. As mentioned above, the following analysis for UIFs is based on 69 valid questionnaires.
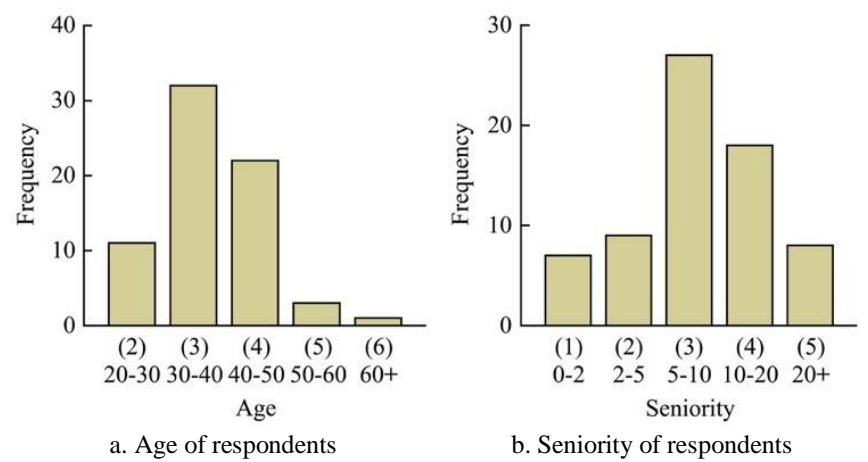

Figure 5 Histogram of respondents' basic information

\subsection{Analyses of $\mathrm{UCIS}$}

\subsubsection{UIFs ranking based on $U C I \mathrm{~s}$}

UCI for each UIF can be calculated as Table 4 shown. This table clearly shows the importance of the UIFs. From ranks 4 and 5, the categories like Nature, Supply, and Demand, are the most important UIFs for farm machinery service.

\subsubsection{Normal distribution test}

Normal distribution of $U C I$ was tested by using one-sample Kolmogorv-Smirnov (K-S) as shown in Figure 6. The test shows that UCIs of UIFs from the questionnaire are normally distributed and has high significance (0.979). Five ranks were decided to be used to further mark the importance of different UIFs based on the distribution of UCIs. Thus, the interval is set to $2.0 / 5=0.4$ and the value starts from zero. Since the range of $U C I$ is from 0 to 4 , the range of $5^{\text {th }}$ rank was extended from $[1.6,2.0]$ to $[1.6,4.0]$ to include all cases.

\subsubsection{General analyses}

Based on Table 4, the distribution histogram of the number of UIFs within each rank is shown in Figure 7 to help to identify the most important UIFs. Only one UIF is in the $5^{\text {th }}$ rank, which has an extreme impact on farm machinery operation and should be always paying attention to. About one-fifth of UIFs belong to the $4^{\text {th }}$ rank, which has a strong impact on farm machinery operation and should be paid more attention to. More than half of the UIFs belong to the $3^{\text {rd }}$ rank, which has an ordinary impact on farm machinery operation and should be emphasized. Nearly one-fifth of UIFs belong to the $2^{\text {nd }}$ rank, which has a weak impact on farm machinery operation and can be ignored in most cases.

Table $4 U C I$ and Rank of case study

\begin{tabular}{|c|c|c|c|c|}
\hline Rank & Item & Category & $U C I$ & Total \\
\hline 5 & sudden weather change & Nature & 1.69 & 1 \\
\hline \multirow{7}{*}{4} & machine degradation & Supply & 1.49 & \multirow{7}{*}{7} \\
\hline & pest or disease outbreak & Nature & 1.43 & \\
\hline & operation area change & Demand & 1.32 & \\
\hline & mechanical failure & Supply & 1.31 & \\
\hline & operation location change & Demand & 1.29 & \\
\hline & soil not suitable for operation & Nature & 1.28 & \\
\hline & obstruction by customer & Interactivity & 1.20 & \\
\hline \multirow{17}{*}{3} & operation order increase & Demand & 1.19 & \multirow{17}{*}{17} \\
\hline & malignant competition & Society & 1.17 & \\
\hline & agronomy incompatibility & Supply & 1.14 & \\
\hline & parts supply delay & Supply & 1.14 & \\
\hline & operation sequence change & Demand & 1.14 & \\
\hline & miscommunication with customer & Interactivity & 1.11 & \\
\hline & operation order cancelation & Demand & 1.11 & \\
\hline & operation duration change & Demand & 1.08 & \\
\hline & operation skill defect & Supply & 1.04 & \\
\hline & maintenance delay & Supply & 1.03 & \\
\hline & operator sudden illness & Supply & 0.99 & \\
\hline & operation price change & Demand & 0.96 & \\
\hline & operation quality change & Demand & 0.87 & \\
\hline & inaccurate farmland location & Interactivity & 0.86 & \\
\hline & machine purchase subsidy change & Society & 0.84 & \\
\hline & way losing & Others & 0.82 & \\
\hline & gas supply delay & Supply & 0.80 & \\
\hline \multirow{7}{*}{2} & operation subsidies change & Society & 0.76 & \multirow{7}{*}{7} \\
\hline & interference by evil forces & Society & 0.71 & \\
\hline & road traffic accident & Others & 0.69 & \\
\hline & production material supply delay & Supply & 0.69 & \\
\hline & unprofessional operation & Interactivity & 0.58 & \\
\hline & government compulsory operation & Society & 0.47 & \\
\hline & government fine & Society & 0.43 & \\
\hline 1 & l & l & l & 0 \\
\hline
\end{tabular}

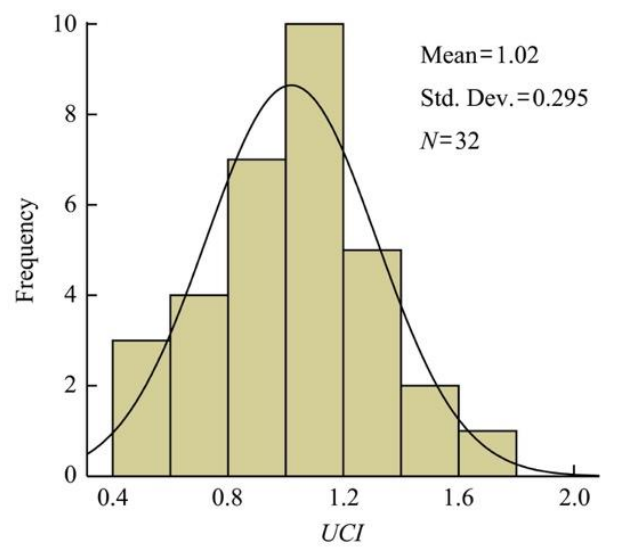

Figure 6 Normal distribution of $U C I$ 


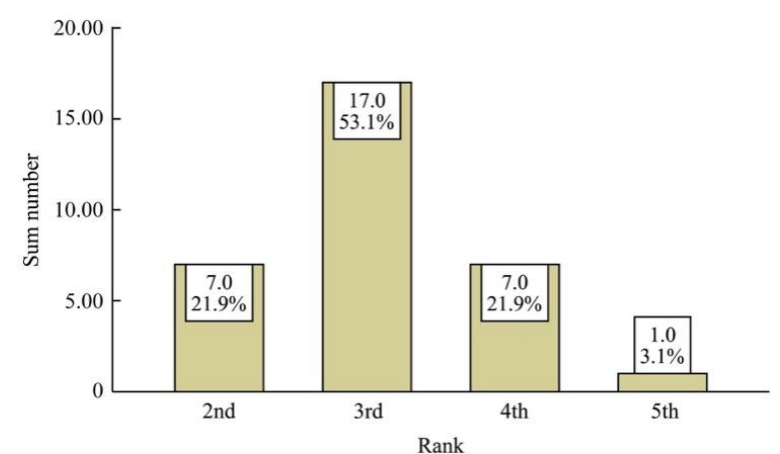

Figure 7 Distribution histogram of the number of UIFs within each rank

Besides identifying the most important UIFs, it is also desired to determine the importance of different UIF categories. Therefore, Table 5 is generated to illustrate the different rank distribution for each category.

Table 5 Category * Rank cross tabulation

\begin{tabular}{|c|c|c|c|c|c|c|c|}
\hline & & & \multicolumn{4}{|c|}{ Rank } & \multirow{2}{*}{ Total } \\
\hline & & & 2nd & $3 \mathrm{rd}$ & 4th & 5 th & \\
\hline \multirow{12}{*}{ Category } & \multirow{2}{*}{ Demand } & Count & 0 & 6 & 2 & 0 & 8 \\
\hline & & $\%$ within category & $0 \%$ & $75.0 \%$ & $25.0 \%$ & $0 \%$ & $100.0 \%$ \\
\hline & \multirow{2}{*}{ Interrelation } & Count & 1 & 2 & 1 & 0 & 4 \\
\hline & & $\%$ within category & $25.0 \%$ & $50.0 \%$ & $25.0 \%$ & $0 \%$ & $100.0 \%$ \\
\hline & \multirow{2}{*}{ Neture } & Count & 0 & 0 & 2 & 1 & 3 \\
\hline & & $\%$ within category & $0 \%$ & $0 \%$ & $66.7 \%$ & $33.3 \%$ & $100.0 \%$ \\
\hline & \multirow{2}{*}{ Others } & Count & 1 & 1 & 0 & 0 & 2 \\
\hline & & $\%$ within category & $50.0 \%$ & $50.0 \%$ & $0 \%$ & $0 \%$ & $100.0 \%$ \\
\hline & \multirow{2}{*}{ Society } & Count & 4 & 2 & 0 & 0 & 6 \\
\hline & & $\%$ within category & $66.7 \%$ & $33.3 \%$ & $0 \%$ & $0 \%$ & $100.0 \%$ \\
\hline & \multirow{2}{*}{ Supply } & Count & 1 & 6 & 2 & 0 & 9 \\
\hline & & $\%$ within category & $11.1 \%$ & $66.7 \%$ & $22.2 \%$ & $0 \%$ & $100.0 \%$ \\
\hline \multirow{2}{*}{ Total } & & Count & 7 & 17 & 7 & 1 & 32 \\
\hline & & $\%$ within category & $21.9 \%$ & $53.1 \%$ & $21.9 \%$ & $3.1 \%$ & $100.0 \%$ \\
\hline
\end{tabular}

All items of natural category belong to the $4^{\text {th }}$ and the $5^{\text {th }}$ rank, which is the most important UIF category. Totally 8 UIFs of Demand category and 8 UIFs of Supply category belong to the $3^{\text {rd }}$ and the $4^{\text {th }}$ rank. In addition, only one UIF of Supply category belongs to the $2^{\text {nd }}$ rank. Three-fourths of UIFs of Interactivity belong to the $3^{\text {rd }}$ and $4^{\text {th }}$ rank. And all items of Others category and Society category belong to the $2^{\text {nd }}$ and $3^{\text {rd }}$ rank. In sum, categories such as Nature, Supply, and Demand, are the most important UIFs for farm machinery service.

\subsection{Analyses of UIF}

\subsubsection{Natural UIF}

Sudden weather change, an UIF of Natural category, has the highest $U C I(1.69)$ and is the only factor of the $5^{\text {th }}$ rank. $V_{O F}$ and $V_{I D}$ are 1.45 and 1.97 , respectively (the maximum among 32 UIFs), which means it happens between occasionally and usually, and moderately impact farm operation. The distributions of occurrence frequency and impact degree of sudden weather change from the questionnaire are shown in Figure 8.
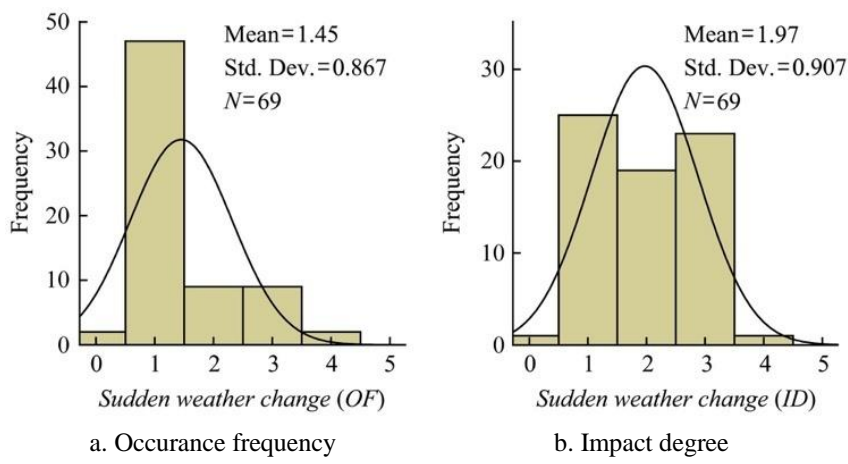

Figure 8 Distribution histogram of $V_{O F}$ and $V_{I D}$ of sudden weather change

Sudden weather change in the open field cannot be controlled by the human. Instead, people are well prepared by improving the weather forecast accuracy. A long-term weather prediction is useful for overall farm machinery operation scheduling, while a short-term and precise weather prediction can be utilized for immediate operation adjusting.

As

Figure $8 \mathrm{~b}$ shows, different operators have different judgments about sudden weather change since different places have different weathers that have different impacts on soil that further influence farm machinery operation. This is not the focus of this study, and the details will not be addressed.

Pest or disease outbreak $(U C I=1.43)$ and soil not suitable for operation (UCI=1.28), UIFs of Natural category listed in the $4^{\text {th }}$ rank, also have serious impacts on farm machinery operation. Forecasting and prevention in advance are important to treat pest or disease outbreak since it has second high value of impact degree (1.67).

\subsubsection{UIF of participants}

(1) Machine health (supply side)

Machine health is quite important to farm machinery operation. Machine degradation (UCI=1.49) and mechanical failure $(U C I=1.31)$ are interpreted as different hints of farm machine unhealthy, both of which are listed in the forefront of the $4^{\text {th }}$ rank. When 
machinery cooperatives suffer from mechanical failure or machine degradation, they have to replace the machine and conduct machine maintenance. However, machine maintenance may also suffer from maintenance delay $(U C I=1.03)$, as shown in Figure 9.

Taking Huishan Company for instance, the most common machine accident is serious damage of expensive headers on the forage harvesters. The giant company, planting about $38000 \mathrm{hm}^{2}$ of silage corn, bought 73 sets of CLAAS Jaguar 850 in 2014. To deal with this uncertainty, the company bought two extra headers for backup purpose. The new header can replace the broken one directly and efficiently to save maintenance time.

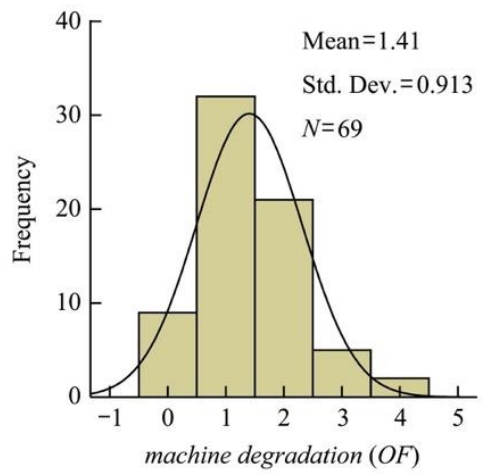

a. OF of machine degradation

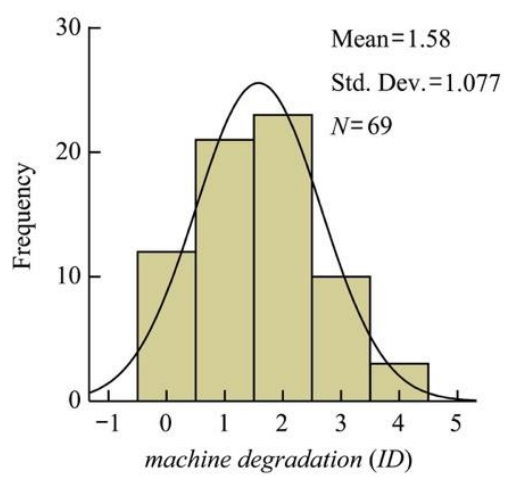

d. ID of machine degradation

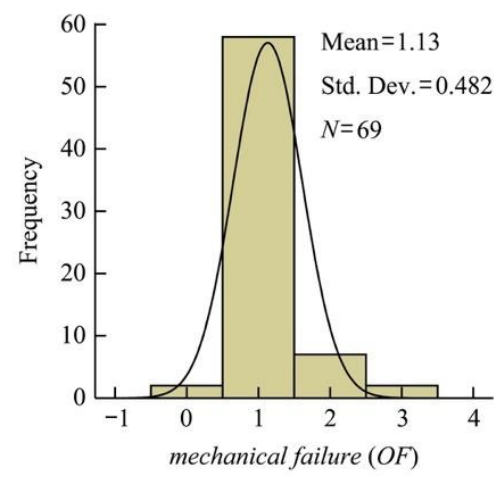

b. OF of mechanical failure

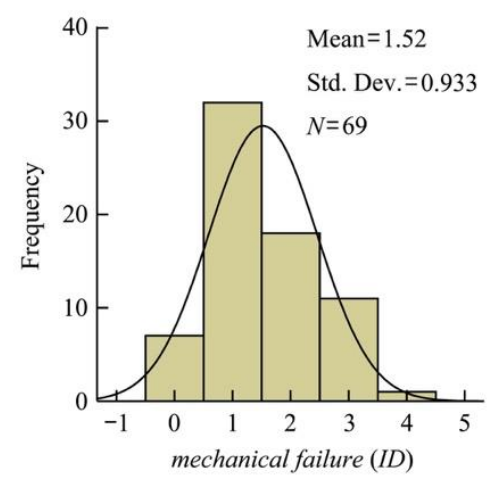

e. ID of mechanical failure

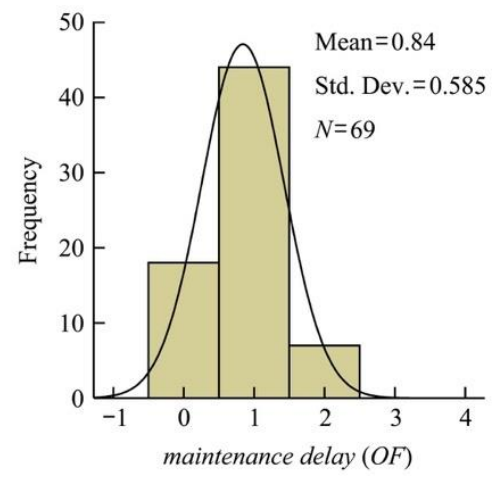

c. OF of maintenance delay

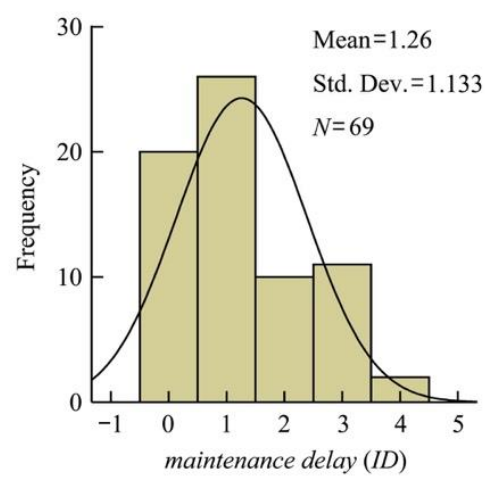

f. ID of maintenance delay

Figure 9 Distribution histograms of OF and ID of machine health and maintenance

(2) Order change (demand side)

Eight UIFs about order change from the demand side belong to the $3^{\text {rd }}$ rank and the $4^{\text {th }}$ rank. Operation area change $(U C I=1.32)$ and operation location change ( $U C I=1.29$ ), belonging to the $4^{\text {th }}$ rank, occur frequently and have a serious impact on the operation schedule. When operation area increases $\left(V_{O F}=1.42\right)$, more work units or working time is required to finish the extra tasks. The distribution histogram shown in Figure 10 indicates the respondents suffer different frequencies and degrees of operation location change.

Among 32 UIFs, operation location change has the maximum value of occurrence frequency $\left(V_{O F}=1.46\right)$, followed by sudden weather change $\left(V_{O F}=1.45\right)$ and operation area change. The investigation shows that operators heavily suffered from location change, since the oral agreement we mentioned in Section 2.1. When the location changes, machinery cooperative has to reschedule the operation plan, and this process is time-consuming and financial wasting, which should be avoided by using formal contrast to reduce the impact of this kind of UIFs.

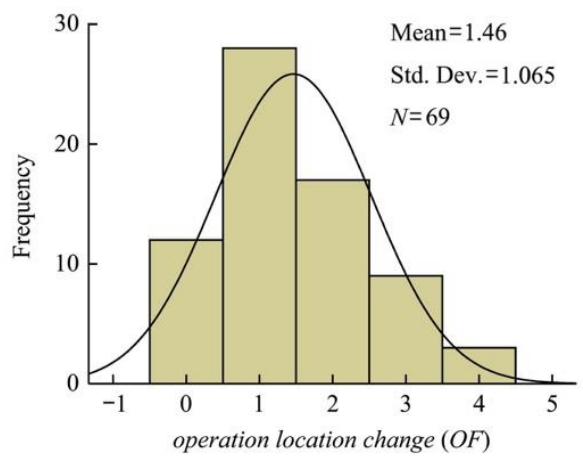

Figure 10 Distribution histogram of OF of operation location change 
Other UIFs such as operation order increase, operation order cancellation, operation sequence change, operation duration change, operation price change, operation quality change, also have great influence on the farm machinery operation. Whether the order increased or canceled before or during operation, cooperative should respond to the change immediately. When customer unilaterally changes the sequence, duration, price, and quality standard, cooperative has to make adjustments and take actions accordingly and even cancel the order after ineffective negotiations. However, the cooperative commonly would like to make concessions to keep their customers.

For the operators, they think that the order requirements of customers are very important and relate to their own interests since they directly face various customers. If the requirements of customer change, it will lead to extra working time and increase the cost of farm machinery operation.

\subsubsection{UIF of interactivity}

Obstruction by the customer is listed in the $4^{\text {th }}$ rank, which is the only UIF in interactivity category. Its $U C I$ is 1.20 and ID is 1.46. These parameters with high value reflect that the farm machinery operation market of social service in China is not mature. Some customers may deliberately bargain the operation price when work unit arrives their farm or lies about their farm area in order to pay less. Therefore, the operation area measurement devices are popular with machinery cooperatives in China.

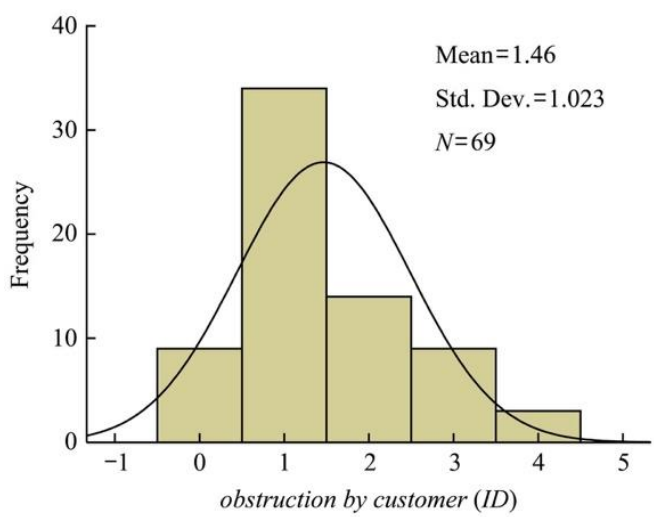

Figure 11 Distribution histogram of ID of obstruction by customer

Miscommunication with a customer (UCI=1.11), listed in the $3^{\text {rd }}$ rank, often happens since deals are made through oral agreement as mentioned in Section 2.1. To sign paper version contract or digital version contract with standard format should be encouraged in future. In fact, some well-developed cooperatives, they begin to sign a formal contract with the customers.

Inaccurate farmland location $(U C I=0.86)$ in the $3^{\text {rd }}$ rank reflects the same problem that limits the execution accuracy of farm operation contract. For an operator in the cooperative from other provinces, it is difficult for him to locate the specific field precisely without digital field map, especially at night. The rural road network is too complex for him.

Subjective bias may inevitably appear in this investigation for the UIF, unprofessional operation. Operators believe accidents caused by them occurred rarely (UCI of unprofessional operation is 0.58). According to their responses, machine healthy is damaged by accident mostly instead of their own mistakes. For this UIF, we claim that objective answers cannot be responded from operators.

\subsubsection{Social UIF}

Malignant competition $(U C I=1.17)$ in the $3^{\text {rd }}$ rank, the highest $U C I$ in a Social category, also indicates that the market is not mature enough in China.

Machine purchase subsidy change (UCI=0.84) is also a factor that will affect farm machinery operation, since the policy will determine how much subsidies cooperatives can get from government, and the compensation will directly impact their attitude to buy new farm machinery or upgrade them alternately.

Other social UIFs listed in the $2^{\text {nd }}$ rank like operation subsidies change (UCI=0.76), interference by evil forces (UCI=0.71), government compulsory operation (UCI=0.47), and government fine (UCI=0.43), have little impact to farm machinery service. However, from another side, it also reflects that current social environment of farm production is relatively stable and health in China. Farm machinery service is mainly controlled by market economy instead of a government, which should be more robust and optimized. In fact, the central and local governments have responsibilities and obligations to serve farmers and farm operations by providing subsidy and information of supply and demand 
to the public.

\section{Conclusions}

In this research, 32 UIFs are defined and classified into six categories according to the production system of farm machinery service. The six categories include demand, supply, interactivity, nature, society and others. $\mathrm{UCI}$, which is the square root of the OF and ID, is defined and determined into five ranks to evaluate the importance of UIF.

To apply the above achievements to analyze the UIFs in farm machinery service, the questionnaire is designed focusing on OF and IF of 32 UIFs and posted online. Statistical analysis is conducted based onUCIs calculated from 69 effective questionnaires. In summary, natural UIFs have a serious impact on farm operation, UIFs of demand and supply have a strong impact on farm operation, UIFs of interactivity have a moderate impact, and social UIFs have a weak impact on farm operation. No doubt, the weather is a key uncertain influence factor. Improving the weather forecast ability will have a significant impact on its influence.

For further research, the feature of uncertainty, e.g. spatial and temporal features ${ }^{[35]}$, and treating strategy should be studied. Overall, uncertainty can easily impact the quality and the efficiency of farm machinery operation and sometimes may cause serious losses. The conclusion of this research mentioned above can be the basis to find the appropriate strategy to eliminate or minimize the impact of UIFs and to improve the efficiency and the profit of farm machinery service, in order to improve the ability of risk management.

\section{Acknowledgements}

We acknowledge the support of National Key Research and Development Program of China (2016YFB0501805), and partly supported by Chinese Universities Scientific Fund (2017QC140). We appreciate the sincere operators from seven provinces who responded the questionnaires. And we also thank Prof. Dirk Hays who gave suggestions to this research during Dr. Wu as a visiting scholar in Texas A\&M University in 2014. Thanks for Mr. Qi Liang, Mr. Li
Jinjiang, Mr. Liu Peng, Ms. Xiang Junhong, Ms. Wang Xinying, Mr. Li Xiaolong, Ms. Pan Changli, et al. who invited operators to finish the questionnaire without pay. And also thanks for graduated student Ms. Zhou Lin who helped the authors to design and post the questionnaire.

\section{[References]}

[1] Mowrer H T. Uncertainty in natural resource decision support systems: Sources, interpretation, and importance. The Scientific Conference on the Application of Scientific Knowledge to Decisionmaking in Managing Forest Ecosystems. 1999, May 3-7. Elsevier, Asheville, NC, USA, pp. $139-154$

[2] Dreyer B, Grønhaug K. Uncertainty, flexibility, and sustained competitive advantage. Journal of Business Research, 2004; 57(5): 484-494.

[3] Lodwick W A. An overview of flexibility and generalized uncertainty in optimization. Computational \& Applied Mathematics, 2012; 31(3): 569-589.

[4] Merschmann U, Thonemann U W. Supply chain flexibility, uncertainty and firm performance: An empirical analysis of german manufacturing firms. International Journal of Production Economics, 2011; 130(1): 43-53.

[5] Pivoto D, Becker J M, Bremm C, Albano F D M. Uncertainty measurement in the homogenization and sample reduction in the physical classification of rice and beans. Ciencia Rural, 2016; 46(4): 599-603.

[6] Sun M, Zhang X, Huo Z, Feng S, Huang G, Mao X. Uncertainty and sensitivity assessments of an agricultural-hydrological model (rzwqm2) using the glue method. Journal of Hydrology, 2016; 534: 19-30.

[7] Nandakumar M, Jharkharia S, Nair A. Environmental uncertainty and flexibility. Global Journal of Flexible Systems Management, 2012; 13(3): 121-122.

[8] Borodin V, Bourtembourg J, Hnaien F, Labadie N. Handling uncertainty in agricultural supply chain management: A state of the art. European Journal of Operational Research, 2016; 254(2): 348-359.

[9] Cowan L, Kaine G, Wright V. The role of strategic and tactical flexibility in managing input variability on farms. Systems Research and Behavioral Science, 2013; 30(4): 470-494.

[10] Milne A E, Glendining M J, Bellamy P, Misselbrook T, Gilhespy S, Casado M R, et al. Analysis of uncertainties in the estimates of nitrous oxide and methane emissions in the uk's greenhouse gas inventory for agriculture. Atmospheric Environment, 2014; 82: 94-105.

[11] Houska T, Multsch S, Kraft P, Frede H G, Breuer L. Monte carlo-based calibration and uncertainty analysis of a coupled 
plant growth and hydrological model. Biogeosciences, 2014; 11(7): 2069-2082.

[12] Vermeulen S J, Challinor A J, Thornton P K, Campbell B M, Eriyagama N, Vervoort J M, et al. Addressing uncertainty in adaptation planning for agriculture. Proceedings of the National Academy of Sciences, 2013; 110(21): 8357-8362.

[13] Jain A, Jain P K, Chan F T S, Singh S. A review on manufacturing flexibility. International Journal of Production Research, 2013; 51(19): 5946-5970.

[14] Adams M L, Cook S, Corner R. Managing uncertainty in site-specific management: What is the best model? Precision Agriculture, 2000; 2(1): 39-54.

[15] Nie J, Sun R, Deng X, Yang H. Uncertain complex event processing in precision agriculture based on data provenance management. Transactions of the CSAM, 2016; 47(5): 245-253. (in Chinese)

[16] Bochtis D D. Concepts and methods for scheduling field machinery operations, In: Hussein M Khodr (Ed.), Computer Science, Technology and Applications. Nova Science Publishers, Incorporated, New York, 2012, pp.179-191.

[17] Guan S, Nakamura M, Shikanai T, Okazaki T. Resource assignment and scheduling based on a two-phase metaheuristic for cropping system. Computers and Electronics in Agriculture, 2009; 66(2): 181-190.

[18] Bochtis D D, Dogoulis P, Busato P, Sørensen C G, Berruto R, Gemtos T. A flow-shop problem formulation of biomass handling operations scheduling. Computers and Electronics in Agriculture, 2013; 91: 49-56.

[19] David A L. Activity network techniques applied to a farm machinery selection problem. Transactions of the ASAE, 1967; 10(3): 0310-0317.

[20] Bochtis D D, Sørensen C G, Green O, Bartzanas T, Fountas S. Feasibility of a modelling suite for the optimised biomass harvest scheduling. Biosystems Engineering, 2010; 107(4): 283-293.

[21] Wu C C, Cai Y P, Luo M J, Su H H, Ding L J. Time-windows based temporal and spatial scheduling model for agricultural machinery resources. Transactions of the CSAM, 2013; 44(5): 237-241, 231. (in Chinese)

[22] Fountas S, Carli G, Sørensen C G, Tsiropoulos Z, Cavalaris C, Vatsanidou A, et al. Farm management information systems: Current situation and future perspectives. Computers and Electronics in Agriculture, 2015; 115: 40-50.

[23] Wu C C, Zhou L, Wang J, Cai Y P. Smartphone based precise monitoring method for farm operation. International Journal of Agricultural and Biological Engineering, 2016;
9(3): 111-121.

[24] Zhang Y, Huang Z H. Identifying risks inherent in farmer cooperatives in China. China Agricultural Economic Review, 2014; 6(2): 335-354.

[25] AhmadA, NabiSTM, FahimeY. Factors affecting pistachio production uncertainty in sirjan. Journal of Agricultural Economics Researches, 2014; 6(3): 175-190.

[26] Yu J, Zhu Q. Agriculture production planning under supply uncertainty and demand uncertainty. 12th International Conference on Service Systems and Service Management, ICSSSM 2015, June 22-24, 2015. Institute of Electrical and Electronics Engineers Inc., Guangzhou, China.

[27] Li E, Yang M, Cook M L. Agricultural machinery cooperatives in china: Origin, development, and innovation. ASABE Annual International Meeting 2009, June 21-24. Reno, NV, United states, pp.5835-5853.

[28] Wu C C, Zhou L, Zhao J, Wang J. Uncertainty of influence factors for farm machinery operation scheduling. ASABE Annual International Meeting 2015, July 26-29. New Orleans, LA, United states, pp.4054-4061.

[29] Bochtis D D, Sørensen C G C, Busato P. Advances in agricultural machinery management: A review. Biosystems Engineering, 2014; 126: 69-81.

[30] Harwood T D, Al Said F A, Pearson S, Houghton S J, Hadley P. Modelling uncertainty in field grown iceberg lettuce production for decision support. Computers and Electronics in Agriculture, 2010; 71(1): 57-63.

[31] Nikkila R, Seilonen I, Koskinen K. Software architecture for farm management information systems in precision agriculture. Computers And Electronics In Agriculture, $2010 ; 70(2): 328-336$

[32] Fountas S, Sorensen C G, Tsiropoulos Z, Cavalaris C, Liakos V, Gemtos T. Farm machinery management information system. Computers and Electronics in Agriculture, 2015; 110: 131-138.

[33] Orfanou A, Busato P, Bochtis D D, Edwards G, Pavlou D, Sørensen C G, et al. Scheduling for machinery fleets in biomass multiple-field operations. Computers and Electronics in Agriculture, 2013; 94: 12-19.

[34] Srensen C G, Bochtis D D. Conceptual model of fleet management in agriculture. Biosystems Engineering, 2010; 105(1): 41-50.

[35] Foy A S, Carstensen L W, Prisley S P, Campbell J B, Dymond $\mathrm{R}$ L. A review and evaluation of uncertainty classification and the error-band geometry model. Transactions in GIS, 2015; 19(4): 604-618. 